\title{
Increasing Interpersonal Interactions in an Online Course: Does Increased Instructor Email Activity and Voluntary Meeting Time in a Physical Classroom Facilitate Student Learning?
}

\author{
Bianca Cung and Di Xu \\ University of California, Irvine \\ Sarah Eichhorn \\ The University of Texas at Austin
}

\begin{abstract}
Distance learning is expanding rapidly in universities. While theoretical and qualitative literature stress the critical role of effective interpersonal interactions in motivating students and facilitating learning in online environments, quantitative evidence on the benefits of increased interpersonal interactions on student learning outcomes is limited. This study examines the effect of providing a voluntary in-person meeting time in a physical classroom and increasing instructor email activity in a fully online precalculus course at a public university. We examine student final exam score and course grade as outcome variables. Student selection into courses was minimal since students only had access to one treatment condition at a time. We further used a propensity score matching strategy to address demographic variations in student characteristics across cohorts. Our results indicate that the increased interpersonal interaction opportunities increased final exam scores by 0.22 standard deviations and improved passing rates by 19 percentage points. Rosenbaum's sensitivity analysis indicates that it is unlikely that these results are due to omitted variable bias.
\end{abstract}

Keywords: at-risk students, computers and learning, educational policy, higher education, instructional technologies, instructional practices

Cung, B., Xu, D., \& Eichhorn, S. (2018). Increasing interpersonal interactions in an online course: Does increased instructor email activity and voluntary meeting time in a physical classroom facilitate student learning? Online Learning, 22(3), 193-215.

doi:10.24059/olj.v22i3.1322

Increasing Interpersonal Interactions in an Online Course: Does Increased Instructor Email Activity and Voluntary Meeting Time in a Physical Classroom Facilitate Student Learning?

Online courses have taken a prominent role at many higher education institutions. Almost all public higher education institutions and two thirds of private institutions in the United States offer online courses (Allen \& Seaman, 2014). Many institutions have been replacing traditional courses taught in physical classrooms with online courses as part of a long-term strategy to address 
Increasing Interpersonal Interactions in an Online Course: Does Increased Instructor Email Activity and Voluntary Meeting Time in a Physical Classroom Facilitate Student Learning?

various institutional concerns, such as faculty and classroom space constraints, increasing enrollment size, and a greater number of adult learners with other responsibilities. This is especially the case for lower division courses with large student enrollments.

One attractive feature of online courses is the ability to use adaptive learning technology to personalize instruction in large enrollment courses, particularly those with students who start off with a varying range of background knowledge on the subject matter. By using algorithms to constantly update and tailor lessons to users, students can work with the computer specifically on topics that they individually do not know. Studies that previously examined online adaptive remedial math courses have found better performance among the online groups in both term-long courses (Fain, 2013) and accelerated summer courses (McGee, Vasquez, \& Cajigas, 2014) compared to traditional term-long courses taught in a physical classroom. However, despite improvements in remediation, a large proportion of students still struggle in online adaptive courses. Students who struggle tend to have lower levels of self-regulation and motivation (Cho \& Heron, 2015).

As with many other fully online courses, researchers are concerned about challenges that may hinder student learning, including the lack of human interaction in virtual learning environments (e.g., Anderson, 2003; Jaggars \& Xu, 2016; Moore, 2013; Moore \& Kearsley, 1996; Scardamalia \& Bereiter, 2006; Su, Bonk, Magjuka, Liu, \& Lee, 2005). Specifically, learning in a virtual learning environment not only imposes physical separation between students and instructors; the physical separation also creates a psychological and communication gap, what Moore (1991) defines as "transactional distance," that leaves room for misunderstanding between instructor and learners. Additionally, the lack of interpersonal connections mitigates students' sense of social presence in the course (Gunawardena \& Zittle, 1997; Short, Williams, \& Christie, 1976; Young, 2006) and works against the formation of a learning community.

In view of the challenges of learning in a fully online course, an extensive theoretical and qualitative literature stresses the critical role of building up effective interpersonal interactions in motivating students and facilitating learning in an online learning environment (e.g., Moore \& Kearsley, 1996; Anderson, 2003; Scardamalia \& Bereiter, 2006). Indeed, nearly every published online quality framework has emphasized the importance of interpersonal communication and collaboration (see Jaggars \& Xu, 2016, for a comprehensive review of online design features).

Despite the consensus achieved regarding the importance of interpersonal communication, research has not yet identified specific ways to improve it in the particular context of college online courses. Instead, colleges and online course instructors are faced with a wide and confusing array of "best practices" that have been recommended under different frameworks for online course design with limited documentation and quantitative evidence on the benefits of these specific strategies.

This study sheds light on this issue by assessing some specific strategies to increase interpersonal interactions in a fully online entry-level college course using the adaptive tutorial system Assessment and Learning in Knowledge Spaces (ALEKS) as the main instructional tool. Specifically, we examine the academic outcomes of students in a fully online precalculus course at a large public four-year university given two conditions. The first condition, which we will refer to as the treatment condition, or the Online with High Interactivity condition (OHI), has frequent and regular email communications initiated by the instructors, in addition to an hour set aside each week for students to optionally meet in a physical classroom. We will refer to activities in which 
Increasing Interpersonal Interactions in an Online Course: Does Increased Instructor Email Activity and Voluntary Meeting Time in a Physical Classroom Facilitate Student Learning?

participants need to be physically present, including the classroom meeting time, as in person.

Emails, which included announcements and reminders to keep students on track, were the primary mode of whole-class communication. The emails contained information that would typically be found in the announcements section of a learning management system (e.g., Jaggars $\& \mathrm{Xu}, 2016)$. One advantage to the whole-class emails over posts in a designated course announcements section was that students could see the reminders before needing to log in to the course learning system, therefore reaching out to students in a more proactive manner. The control condition, or the Online with Low Interactivity condition (OLI), follows the typical design of fully online courses with a limited number of instructor emails and no organized in-person interactions. We took advantage of the fact that during the period of this study, only one treatment condition was offered during a particular term, and students were not aware which condition was offered when they enrolled in the course, thereby minimizing potential self-selection. We further used a propensity score matching strategy to address potential variations in baseline characteristics of the students enrolled in the course over time. The course structure was predetermined by the department, and in both years included in our study, the course used the same syllabus, online learning materials, and the same set of test banks for the final exam. We used several different course performance measures, including course grades, course passing rate, and a subset of questions from the final exam based on the same test bank, to uncover whether more regular instructor emails and voluntary face-to-face meeting time for answering student questions could improve student learning outcomes in this high-demand lower division developmental math course.

It is worth noting that our focus on the precalculus course is of particular importance for educational policy. First, remedial education has increasingly become an important feature of the U.S. higher education. Nationally, one third of college freshmen and sophomores take at least one remedial course in college (Skomsvold, 2014). Moreover, the remedial courses are also associated with particularly high failure rates. Based on student transcript data from a nationwide sample, a recent report by the U.S. Department of Education indicates that the number of postsecondary students who have ever enrolled in remedial coursework is closer to one half, with only $70 \%$ of the enrolled remedial coursework resulting in a passing grade (Radford \& Horn, 2012). Among the large proportion of undergraduates that place into at least one remedial course, mathematics has the highest rate of remediation (Attewell, Lavin, Domina, \& Levey, 2006; Chen \& Simone, 2016; Parsad, Lewis, \& Greene, 2003; Skomsvold, 2014; Sparks \& Malkus, 2013) but the lowest rate of successful remediation (Bahr, 2011; Bonham \& Boylan, 2011). Finally, due to the high demand and large volume of enrollment, lower level courses, such as developmental coursework, are most likely to be substituted by online learning. This is worrisome considering that recent studies have consistently found that academically underprepared students may struggle particularly in online learning (Asarta \& Schmidt, 2017; Figlio, Rush, \& Yin, 2013; Xu \& Jaggars, 2014). Therefore, documenting and empirically evaluating the impacts of specific strategies and practices on student learning outcomes in precalculus online courses is of first-order priority.

Overall, this study seeks to answer the following research question: Do increased interpersonal interactions, as afforded by frequent instructor emails and the opportunity to meet in a physical classroom environment on a voluntary basis, improve student course performance? Our findings indicate that interpersonal interactions significantly improve student course performance in terms of all outcome measures, where the most convincing evidence is from the subset of final exam questions based on the same test bank. Our subsequent Rosenbaum's sensitivity analysis 
Increasing Interpersonal Interactions in an Online Course: Does Increased Instructor Email Activity and Voluntary Meeting Time in a Physical Classroom Facilitate Student Learning?

(Rosenbaum, 2005) indicates that it is highly unlikely that these results are due to omitted variable bias. The evidence therefore suggests that students' achievement in an online course can be greatly enhanced with well-structured interpersonal communication through email and a weekly one-hour in-person meeting time for answering student questions.

\section{Review of Related Literature}

Interpersonal interaction is thought to play an important role in student learning (Moore \& Kearsley, 1996; Anderson, 2003; Scardamalia \& Bereiter, 2006). Collaborative work, for example, provides cognitive support and encourages critical thinking, problem solving, and deeper learning through the formation of a learning community (Fulford \& Zhang, 1993; Kearsley, 1995; Moore \& Kearsley, 1996; Friesen \& Kuskis, 2013; Picciano, 2001; Salmon,

2002, 2004; Scardamalia \& Bereiter, 2006; Sherry, 1995). Additionally, effective interpersonal interaction can enhance students' sense of "social presence"- the degree to which a person is perceived as a "real person" in mediated communication-and thereby support students' psychological connection to the course (e.g., Gunawardena \& Zittle, 1997; Shearer, 2013; Short, Williams, \& Christie, 1976; Young, 2006). One meta-analysis examining studies of interaction in online learning environments concluded that increased interpersonal interaction, either with the instructor or other peers, positively affects student learning (Bernard et al., 2009). Among the many possible paired interaction combinations, learner-instructor interactions have been found to be the most significant factor in predicting perceived learning outcomes in online environments (Fredericksen, Pickett, Shea, Pelz, \& Swan, 2000; Jiang \& Ting, 1999; Swan et al., 2000).

Learners' perceptions of the quality of learner-instructor interactions are also an important predictor of learners' overall satisfaction in an online learning environment (Kang \& Im, 2013).

Unfortunately, it is particularly challenging to implement effective interpersonal interactions in an online course. The distance created by online learning environments detracts from a sense of social belonging while also creating a sense of isolation, frustration, and boredom (Berge, 1999; Hara, 2000; Northrup, 2002; Young, 2006). In turn, the lack of peer and learnerinstructor interactions can impact students' motivation and cognitive processes (Schunk, Pintrich, $\&$ Meece, 2008). To address the lack of interactivity in an online learning environment, researchers consistently agree that online instructors need to pay special attention to facilitate interactions in an online learning environment (An, Shin, \& Lim, 2009; Berge, 1999; Cho \& Cho, 2016; Cho \& Kim, 2013; Hew, Cheung, \& Ng, 2010; Mandernach, Forrest, Babutzke, \& Manker, 2009; Moore, 1989).

Among the many forms that interpersonal interaction can take in an online learning environment (Chou, 2003), email is one such interpersonal communication mode that the instructor can actively initiate. Although instructor emails are widely used across online courses, they have been found to vary substantially in length, meaningfulness, and frequency (Hassini, 2006), which in turn may have different influences on the interactivity of the online learning environment. In a recent study that links online course design features with student learning outcomes from 23 high-volume lower division online college courses (Jaggars \& Xu, 2016), for example, the researchers found that "high-interaction instructors posted announcements on a regular basis to remind students about requirements for assignments, coming deadlines, newly posted documents, examinations, and other logistic issues" (p. 278), and that such high interaction 
Increasing Interpersonal Interactions in an Online Course: Does Increased Instructor Email Activity and Voluntary Meeting Time in a Physical Classroom Facilitate Student Learning?

is positively related to student learning outcomes. In contrast, in courses where the instructor posted announcements and reminders to students on a limited basis, students were more likely to express dissatisfaction with the course.

Another means of increasing interpersonal interaction is by providing synchronous communication opportunities, especially through in-person interactions. This often takes place through in-person office hours, which have been seen as an opportunity for help seeking outside of the classroom (Acitelli, Black, \& Axelson, 2003). However, existing studies suggest that office hour visits are generally brief and underutilized (Bippus, Kearney, Plax, \& Brooks, 2003; Griffin et al., 2014; Jaasma \& Koper, 1999; Nadler \& Nadler, 2000), which is partly due to students' discomfort in one-on-one conversations with the course instructor. Based on these concerns, some educators have recommended alternatives that would increase the chances of making use of inperson discussions, such as structured topical office hours and group discussion sections (e.g., Weimer, 2015). Despite these theoretical discussions, the use and possible impact of a voluntary group meeting time for answering student questions in a fully online course has not yet been empirically examined.

The current study addresses this literature gap by examining student performance in a fully online math course taught under two conditions: (1) a control condition with minimal numbers of instructor emails and no reserved classroom space for in-person meetings and (2) a treatment condition with more frequent instructor whole class communications and a weekly one-hour inperson meeting time for answering student questions. Though all students were highly encouraged to attend the in-person meeting, record of attendance was not kept, and students were not penalized for skipping the meetings. As such, the in-person discussion section was completely voluntary and was comparable to other voluntary in-person interaction opportunities, such as office hours.

\section{Research Context}

\section{Methods}

This study examines a precalculus course taught at a large public four-year university in the western United States. The precalculus course is a prerequisite for calculus, which is generally required across all STEM-related majors. Students who need to take calculus can skip the precalculus course by scoring at least a 3 on the Advanced Placement Calculus exams, scoring at least 600 on the SAT Math portion, or passing a placement exam. Overall, about 350 students, three percent of the incoming freshman class, take precalculus in their first year.

Two years of data are included in the analysis, starting from the 2012-2013 academic year through the 2013-2014 academic year. The data for this study comes from two sources: the Office of Institutional Research (OIR) and the online instructional system used in the course, ALEKS. The OIR dataset includes information about students' academic and demographic background, such as students' final grade in the course, SAT scores, major, year of initial enrollment, gender, and ethnicity. The ALEKS dataset contains students' initial assessment score in precalculus, instructor emails, and final exam score with details for each question in the exam.

Prior to the fall of 2012, precalculus was offered through a blended delivery format with three 1-hour, in-person lectures in a physical classroom per week in conjunction with online ALEKS tutorials. Starting in the fall of 2012, however, the university converted precalculus into a fully online course taught through ALEKS; students did not physically meet for lectures and instead worked individually through the ALEKS instructional system. In both years included in 

and Voluntary Meeting Time in a Physical Classroom Facilitate Student Learning?

our study, the course used the same syllabus, online learning materials, and the same set of test banks for the final exam.

The initial assessment is an adaptive questioning system that pulls items from a test bank on ALEKS. It gauges each student's content knowledge upon initial login. Following the initial assessment, ALEKS determines lessons that the student has already mastered and has yet to master. Throughout the school term, students work individually on topics that they have yet to master. ALEKS adapts its suggested topics, grouped into larger categories, for the students to work on based on the students' recent progress. Since students worked on ALEKS individually and at different paces, the instructor held more of a support role in answering student questions as they arose and enforcing deadlines for topic categories in ALEKS.

Across all terms in this study, students took their final exam on ALEKS. A total of 40 different question items were randomly generated on ALEKS, though the school's math department was able to predetermine which topic would be tested in each question item. All the exam questions were randomly drawn from ALEKS' test bank based on the predetermined composition of topics. The specific set of topics covered during the final exam changed slightly between the two academic years. However, for a particular topic (such as "Double-Angle Identities"), students taking the course in different terms were subject to the same test bank. A total of 26 questions out of 40 tested were drawn from the same topics across the four terms included in our study.

Precalculus was only offered during the fall and winter quarters, and a total of 1,485 students were enrolled in precalculus across the four academic school terms. We limited the analysis to 1,003 first-time and nontransfer enrollees in precalculus and additionally excluded 40 students who were missing information on key demographic variables. The final analytic sample consists of 963 students. Enrollment counts by term can be found in Table 1.

\section{Table 1}

Enrollment Counts by Term

\begin{tabular}{lccc}
\hline & In-Person Support & Total & Analysis Sample \\
\hline Fall 2012 & No & 503 & 328 \\
Winter 2013 & No & 330 & 177 \\
Fall 2013 & Yes & 417 & 310 \\
Winter 2014 & Yes & 235 & 148 \\
\hline Total & & 1,485 & 963 \\
\hline
\end{tabular}

\section{Course Format Description}

Online with low interactivity (control condition). The precalculus course with low interactivity (referred to as the OLI course or control group hereafter) was offered in the 20122013 academic year. Two course sections, each taught by a different instructor, were offered during fall 2012. Only one section was taught during the winter 2013 term, and it was taught by one of the instructors from the fall 2012 term. Instructors were available throughout the week in both in- person and online office hours. Instructors answered individual student emails but also initiated whole-class emails. While students could find key information on the course web page, the instructor used the whole-class emails to serve as a means to proactively communicate with students and keep them on track. Column 1 in Table 2 summarizes the frequency of whole-class 
instructor emails and breaks down these emails by their primary purpose. On average, the three sections had 2.77 instructor-initiated emails to the whole class per week. The majority of these emails were either about office hours $(38.55 \%)$ or course logistics $(36.14 \%)$, including one or two welcome emails per section. Only $2.41 \%$ of the emails were about the course content. The remaining emails were either about the exams ( $14.46 \%$ for the midterm and $6.02 \%$ for the final) or reminders $(2.41 \%)$.

Table 2

Instructor-Initiated Emails by Content

\begin{tabular}{lcc}
\hline & OLI, 2012-13 (\%) & OHI, 2013-14 (\%) \\
\hline Logistics and Welcome & 36.14 & 34.25 \\
Office Hours & 38.55 & 12.71 \\
Reminders & 2.41 & 19.89 \\
Content & 2.41 & 7.73 \\
Midterm Related & 6.02 & 5.52 \\
Final Exam Related & 14.46 & 7.73 \\
Discussion Section & - & 17.13 \\
\hline Average \# Emails Per Week & 2.77 & 6.25 \\
\hline
\end{tabular}

It is worth noting that the grading scheme varied slightly between fall and winter terms. In fall 2012, the midterm and final exam were worth $30 \%$ and $40 \%$ of students' grades, respectively. The remaining 30\% was based on one office hour attendance (2\%) and four ALEKS milestones, each worth $7 \%$ of the final grade. In winter 2013, the department modified the grading scheme of the precalculus course. The midterm and final exam were worth $25 \%$ and $40 \%$, respectively. The course additionally had six milestones ( $4 \%$ each), four quizzes ( $2 \%$ each), and an orientation quiz $(3 \%)$. With the exception of shorter intervals between milestones and the incorporation of online quizzes, the winter 2013 precalculus offering was similar to fall 2012 in students' amount of contact with the instructor.

Online with high interactivity (treatment condition). The sections offered during the 2013-2014 academic year were nearly identical to the winter 2013 precalculus offerings, with each of the 10-week courses outlined the same as the winter OLI course. Quizzes and milestones were also due on the same week numbers. The grading scheme was also the same as that of the winter 2013 section. However, there were two primary differences between the online with high interactivity course (referred to as OHI course or treatment group hereafter) and the OLI course.

First, an hour classroom time was reserved weekly for students to voluntarily meet in a physical lecture hall with the instructor (referred to as discussion section hereafter). The lecture hall had room for over 300 students, which was well over the enrollment count. Students were encouraged to submit questions prior to the discussion section through emails with regard to the course materials covered during that week. The instructor used the physical classroom meeting time to answer student questions that were either collected through emails or raised during the discussion section. The discussion section was completely voluntary, and students were not required to attend the session. According to the course instructors, the majority of the students attended the first session, but the attendance rate declined to around $25 \%$ afterward. The weekly $25 \%$ attendance rate is, nevertheless, substantially higher than the typical usage of instructors' office hours in either the OLI or OHI conditions. 
Increasing Interpersonal Interactions in an Online Course: Does Increased Instructor Email Activity and Voluntary Meeting Time in a Physical Classroom Facilitate Student Learning?

Second, the two instructors who taught during the fall 2013 term were different from the instructors who taught during the 2012-2013 academic year. One of the instructors who taught during the fall 2013 term also taught during the winter 2014 term. However, since the course structure was predetermined by the department with an online work schedule and materials that were identical to those of the winter 2012-2013 term, each instructor's predominant influence on the course took place through email communication and the physical classroom meetings. Wholeclass emails for the OHI sections were sent much more frequently, averaging 6.25 times a week, which is more than twice as frequent as the instructor-initiated emails in the OLI condition.

Column 2 in Table 2 further breaks down the emails sent to the whole class by their content. It is worth noting that due to the higher frequency of emails overall, the OHI condition outnumbered the OLI condition almost in every type of email except for office hours. Hence, below we focus on the proportion of different types of emails to shed light on whether the instructors also differed in their focus in sending these emails between the two years.

Similar to the OLI courses, a large proportion of the instructor-initiated emails in the OHI condition were also about course logistics (34.25\%). Probably due to the additional discussion sections, there were proportionately fewer emails about office hours than the OLI condition $(12.71 \%)$, but a substantial proportion of emails about the discussion section $(17.13 \%)$. The most striking differences between the OLI and OHI conditions lie in reminders and content-related emails. Compared to the OLI condition, the OHI conditions proportionately sent 8 times more reminder emails $(2.41 \%$ vs. $19.89 \%)$. These emails were sent on a weekly regular basis, mainly to keep students on track. There was also a substantially larger proportion of course-content-related emails sent in the OHI condition (7.73\% vs. $2.41 \%)$, a handful of which included example problems.

\section{Methods}

\section{Outcome Measures}

We examined the impact of OHI relative to OLI on student performance through two outcome measures: a final exam subscore calculated from overlapping topics tested in all four terms and final course grade.

The full final exam consisted of 40 question items. The actual questions posed varied from student to student, but all were randomly generated on ALEKS from a set of question banks. Each question bank corresponded to a course topic. However, as mentioned above, the specific set of topics covered during the final exam changed slightly across terms. One potential problem associated with such term-by-term variations was that the final exam score might not have been directly comparable across terms due to different sets of topics covered during the exam. For example, if the topics selected by the department in 2013 tended to be slightly easier than those in 2012, the average difference in the final exam score may have actually reflected the difficulty of the exam rather than learning outcomes.

To enable fair comparisons across terms, we examined the final exam subscore as a percentage score (points earned divided by total points possible). The final exam subscore was calculated from using only question topics covered across all four quarters. As a robustness check, we used the raw final exam score and found fairly similar results. Since the same question bank was used for particular topics, such as "Double-Angle Identities," students' scores for that topic 
were directly comparable across terms. A total of 26 questions out of 40 tested were drawn from the same topics across the four terms. As such, only 26 items were included in the calculation of the final exam subscore.

We additionally examined course grades, as they were an important reflection of each student's overall success in a course. We looked particularly at the grades from winter 2012 and after, since the grading schemes and weight distribution were the same across these three terms. We converted course letter grades to a 4-point numeric scale. The grades B- and B+, for example, equated to 2.7 and 3.3 grade points, respectively. The grade $\mathrm{F}$ equated to 0 grade points. We used 4.3 to represent $\mathrm{A}+$ in order to distinguish the higher valued $\mathrm{A}$ grade, even though the school calculates both $\mathrm{A}+$ and $\mathrm{A}$ as 4 grade points. A small number of students $(n=58)$ took precalculus on a pass/no pass grading scale. These students were included in our primary analysis, where a "pass" grade equated to 2 grade points (the equivalent of a C) and a "no pass" grade equated to 0 grade points. In a separate robustness check, we also excluded these students from the sample, and the results remained the same.

\section{Propensity Score Matching (PSM)}

One advantage of this dataset is that only one condition (OLI or OHI) was offered at a time. Students could only self-select into a different course format if they delayed taking precalculus for a different year. However, this decision was unlikely to happen because the course was a prerequisite to many STEM courses. Since many of the courses were sequence courses and also had calculus as further prerequisites, postponing the precalculus course could greatly delay graduation. Furthermore, students were not guaranteed a different instructional format if they delayed taking precalculus because they did not know what format future courses would be taught in. The remaining concern, therefore, would be possible variations between cohorts in student characteristics.

Specifically, although only one treatment condition was offered during a particular term, which minimized potential self-selection, we were still concerned that the composition of student demographics and abilities might have been different between the OLI and the OHI groups. Although the raw comparison between the two groups presented in Table 3 (mean differences based on the "unmatched" sample) indicated that the students taking the course in the 2013-2014 school year (the OHI group) had similar initial ALEKS assessment scores compared to students taking the course in the 2012-2013 school year (the OLI group), some other significant differences emerged across the two groups. For example, the OHI group had significantly lower SAT scores and also had a higher proportion of students who declared in majors that required math courses. This was partly due to the fact that during the past few years, the university where this study was conducted had been steadily increasing enrollment of state residents and lowering admission criteria, especially in STEM-related fields. As a result, this led to disproportionate increases in the fraction of at-risk students being accepted to campuses and STEM-related fields. 
Table 3

Pooled PSM Balance Check for Fall and Winter Students

\begin{tabular}{|c|c|c|c|c|c|c|c|}
\hline \multicolumn{5}{|l|}{ Mean } & \multicolumn{3}{|c|}{ Standard Deviation } \\
\hline Variable & & $\begin{array}{c}\text { OLI } \\
2012-13\end{array}$ & $\begin{array}{c}\text { OHI } \\
2013-14\end{array}$ & Diff. & $\begin{array}{c}\text { OLI } \\
2012-13\end{array}$ & $\begin{array}{c}\text { OHI } \\
2013-14\end{array}$ & Ratio \\
\hline Initial Assessment & Unmatched & 23.45 & 24.19 & -0.05 & 14.82 & 15.84 & 0.94 \\
\hline Matched & & 21.53 & 21.16 & 0.03 & 9.73 & 9.09 & 1.07 \\
\hline SAT Math Score & Unmatched & -0.69 & -0.80 & 0.20 & 0.54 & 0.72 & 0.76 \\
\hline Matched & & -0.72 & -0.76 & 0.07 & 0.48 & 0.49 & 0.99 \\
\hline SAT Verbal Score & Unmatched & -0.86 & -1.05 & 0.27 & 0.72 & 0.85 & 0.84 \\
\hline Matched & & -0.93 & -0.99 & 0.08 & 0.60 & 0.62 & 0.96 \\
\hline Female & Unmatched & 0.62 & 0.61 & 0.03 & 0.49 & 0.49 & 0.99 \\
\hline Matched & & 0.65 & 0.65 & 0.00 & 0.48 & 0.48 & 1.00 \\
\hline \multicolumn{8}{|l|}{$\overline{\text { Ethnicity }}$} \\
\hline Asian & Unmatched & 0.26 & 0.31 & -0.11 & 0.44 & 0.46 & 0.95 \\
\hline Matched & & 0.27 & 0.27 & 0.00 & 0.45 & 0.45 & 1.00 \\
\hline Black & Unmatched & 0.05 & 0.05 & 0.01 & 0.22 & 0.21 & 1.03 \\
\hline Matched & & 0.02 & 0.02 & 0.00 & 0.15 & 0.15 & 1.00 \\
\hline Hispanic & Unmatched & 0.48 & 0.45 & 0.06 & 0.50 & 0.50 & 1.00 \\
\hline Matched & & 0.59 & 0.59 & 0.00 & 0.49 & 0.49 & 1.00 \\
\hline White & Unmatched & 0.11 & 0.11 & -0.01 & 0.31 & 0.32 & 0.99 \\
\hline Matched & & 0.08 & 0.08 & 0.00 & 0.27 & 0.27 & 1.00 \\
\hline Other & Unmatched & 0.10 & 0.08 & 0.07 & 0.30 & 0.27 & 1.11 \\
\hline Matched & & 0.04 & 0.04 & 0.00 & 0.20 & 0.20 & 1.00 \\
\hline Major Requires Math & Unmatched & 0.42 & 0.58 & -0.31 & 0.49 & 0.49 & 1.00 \\
\hline Matched & & 0.44 & 0.44 & 0.00 & 0.50 & 0.50 & 1.00 \\
\hline Freshman & Unmatched & 0.81 & 0.78 & 0.09 & 0.39 & 0.42 & 0.94 \\
\hline Matched & & 0.87 & 0.87 & 0.00 & 0.33 & 0.33 & 1.00 \\
\hline
\end{tabular}

Note. "Matched" shows the matched estimates using Mahalanobis distances and kernel matching with a bandwidth of 1.5. Students in the treatment group received in-person support while students in the control group did not. SAT Math and Verbal scores are centered at a score of 600 (the cutoff score for students who would like to skip to the next math course) and have been divided by 100 .

To address baseline differences between students taking the course in different terms, we used a propensity score matching (PSM) strategy to generate two comparable groups by selecting similar students in each condition. Specifically, we chose students from the OLI group who resembled students from the OHI group based on all observable demographic and ability characteristics and then discarded dissimilar OLI students who failed to be matched to an OHI student.

PSM is a two-step process that involves first mapping a series of covariates onto a unidimensional value (a propensity score) that represents the probability of being in the OHI group or not. For this first step, we used logistic regression to calculate each individual's propensity score. Based on the consideration that there may have been differences in student characteristics based on the term that they take precalculus (e.g., weaker students may hold off on taking 
precalculus until winter), we estimated the logistic regressions on the fall cohorts and winter cohorts separately and matched fall students to fall students and winter students to winter students only. The results from the logistic regression estimation of students' probability of being in the OHI condition are presented in Table 4. In the second step, propensity scores for each person in the two groups were matched so that the treatment and control groups were similar. We used Mahalanobis distances and kernel matching with a bandwidth of 1.5 and with replacement.

Table 4

Logistic Regression for OHI Enrollment Propensity Score

\begin{tabular}{lcc}
\hline & Fall Terms & Winter Terms \\
\hline Initial Assessment & -0.01 & -0.00 \\
Sqrt(Initial Assessment) & $(0.03)$ & $(0.04)$ \\
\multirow{2}{*}{ SAT Math Score } & 0.03 & -0.03 \\
& $(0.28)$ & $(0.44)$ \\
SAT Verbal Score & 0.17 & $0.55^{*}$ \\
& $(0.16)$ & $(0.25)$ \\
Female & $0.22+$ & $0.55^{* *}$ \\
Ethnicity & $(0.12)$ & $(0.18)$ \\
Asian & 0.12 & 0.16 \\
& $(0.17)$ & $(0.26)$ \\
Black & & \\
& -0.20 & 0.32 \\
Hispanic & $(0.29)$ & $(0.45)$ \\
& 0.20 & 0.80 \\
Other & $(0.45)$ & $(0.65)$ \\
& 0.31 & 0.51 \\
Major Requires Math & $(0.27)$ & $(0.45)$ \\
Freshman & $0.69+$ & -0.03 \\
& $(0.39)$ & $(0.62)$ \\
Constant & $-0.85^{* * *}$ & -0.29 \\
& $(0.17)$ & $(0.24)$ \\
$N$ & $0.58^{* *}$ & -0.10 \\
& $(0.21)$ & $(0.30)$ \\
\hline
\end{tabular}

Note. Standard errors in parentheses. "White" is the base case for ethnicity. SAT Math and Verbal scores are centered at a score of 600 and have been divided by 100 .

$+p<.10 . * p<.05 . * * p<.01 . * * * p<.001$.

Covariates for matching included initial assessment score, SAT Math and Verbal scores, gender, ethnicity, whether the student declared a major that requires math, and whether the student was in his or her first year at the university. Some researchers (e.g., Austin, 2011) suggested adding nonlinear terms of covariates to achieve balance in the standard deviation given that the purpose of PSM was to achieve balance in the entire distribution of baseline covariates. We included the square root of initial assessment score since students with low scores had a lot of room for improvement, while students with high scores only needed to go over a few concepts. 

and Voluntary Meeting Time in a Physical Classroom Facilitate Student Learning?

The comparison between the OLI and OHI conditions based on the matched sample in Table 3 indicated that the two groups were fairly balanced in terms of both means and standard deviation of all the key variables: specifically, we used the standardized difference-calculated as the absolute difference in each variable's mean across the OLI and OHI groups and divided by the pooled standard deviation of the variable - to assess the difference in means between the treatment and control group. For the standard deviations, we found the standard deviation ratio for each variable, computed as the ratio of the OLI group standard deviation to the OHI group standard deviation. As shown in Table 3, the OHI and OLI groups were fairly balanced, with a standardized difference of at most 0.1 and a standard deviation ratio between 0.8 and 1.25 . We also checked the balance for the subsample of students who took precalculus during the fall terms and winter terms, respectively. The results for the balance checks are presented in Appendix Tables 1 and 2, and are fairly similar to those presented in Table 3 .

The balance achieved through PSM procedures was also reflected in the overall distribution of scores in each term. Figure 1 shows the kernel density plots of the pre- versus postmatch distributions of the propensity scores for the OHI and OLI groups in fall term and winter term, respectively. Both terms had an overlapping region of common support between the OLI and OHI conditions, and the distributions between OLI and OHI students became almost identical after matching. These results, therefore, justified the comparisons between the OLI and OHI conditions based on the matched sample.
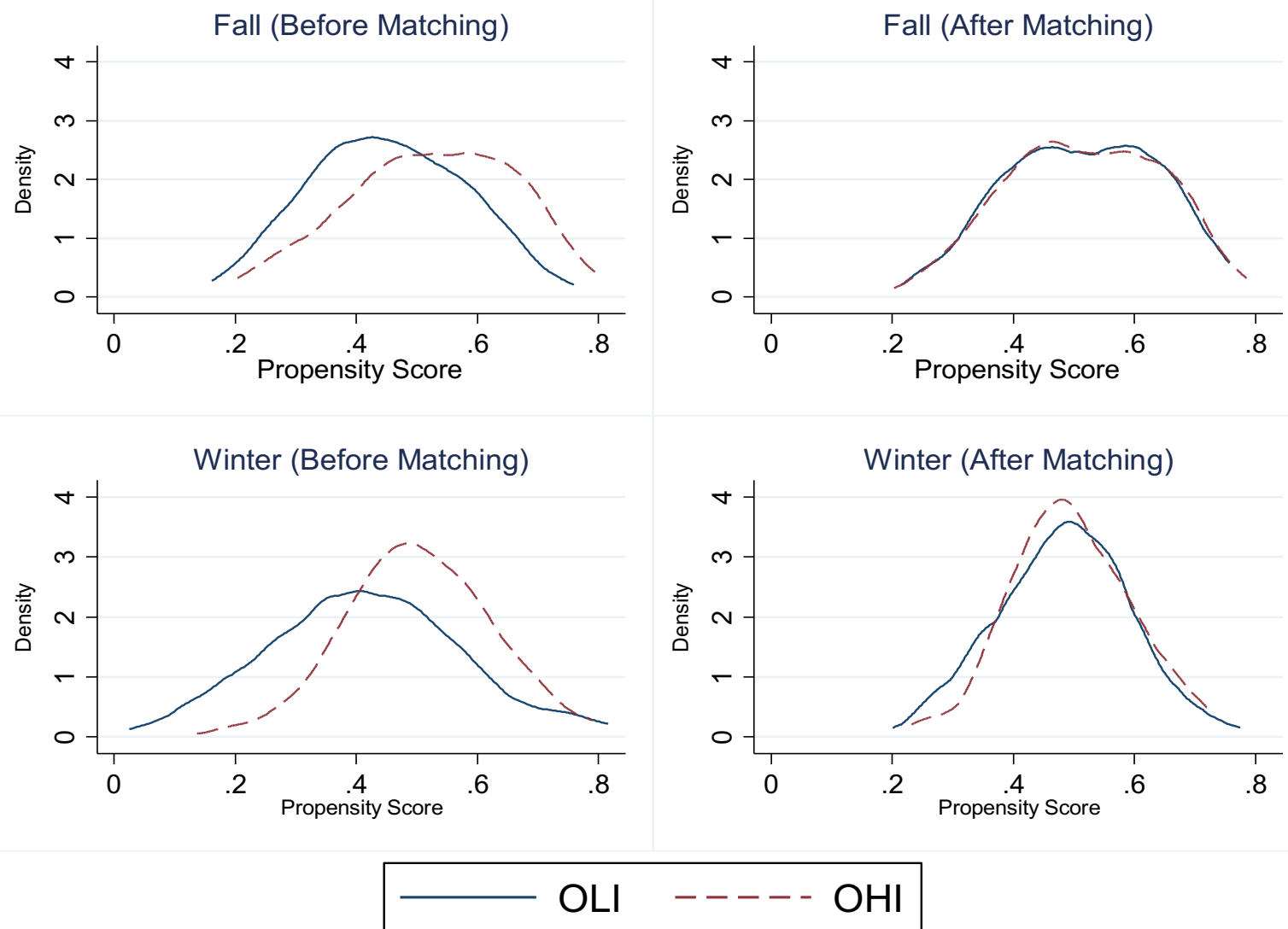

Figure 1. Propensity score pre- and postmatch distribution. 

and Voluntary Meeting Time in a Physical Classroom Facilitate Student Learning?

Finally, although we were able to achieve balance in terms of observable student characteristics, we were still concerned that our models might face the threat of missing variable bias. We therefore used Rosenbaum's sensitivity analysis (Rosenbaum, 2005) to examine the magnitude of the missing variable needed to negate our results.

\section{Results}

Figure 2 shows the grade distribution in each instructional condition. Overall, the OHI students had a higher final exam subscore $(70.35 \%)$ than the OLI students $(64.96 \%)$. Table 5 presents the estimated treatment effects of providing high-level interactivity $(\mathrm{OHI})$ in the precalculus course on student final exam scores based on test items drawn from the same test bank. Column 1 presents estimated effect of $\mathrm{OHI}$ based on the matched sample across all the four terms; Column 2 and Column 3 focus on the fall and winter terms, respectively, to address the possibility that the impact might be different on the fall and winter cohorts. Finally, Column 4 presents estimates based on the pooled sample again but includes additional interaction terms between OHI and a dummy variable indicating whether the term is winter quarter (versus fall quarter).

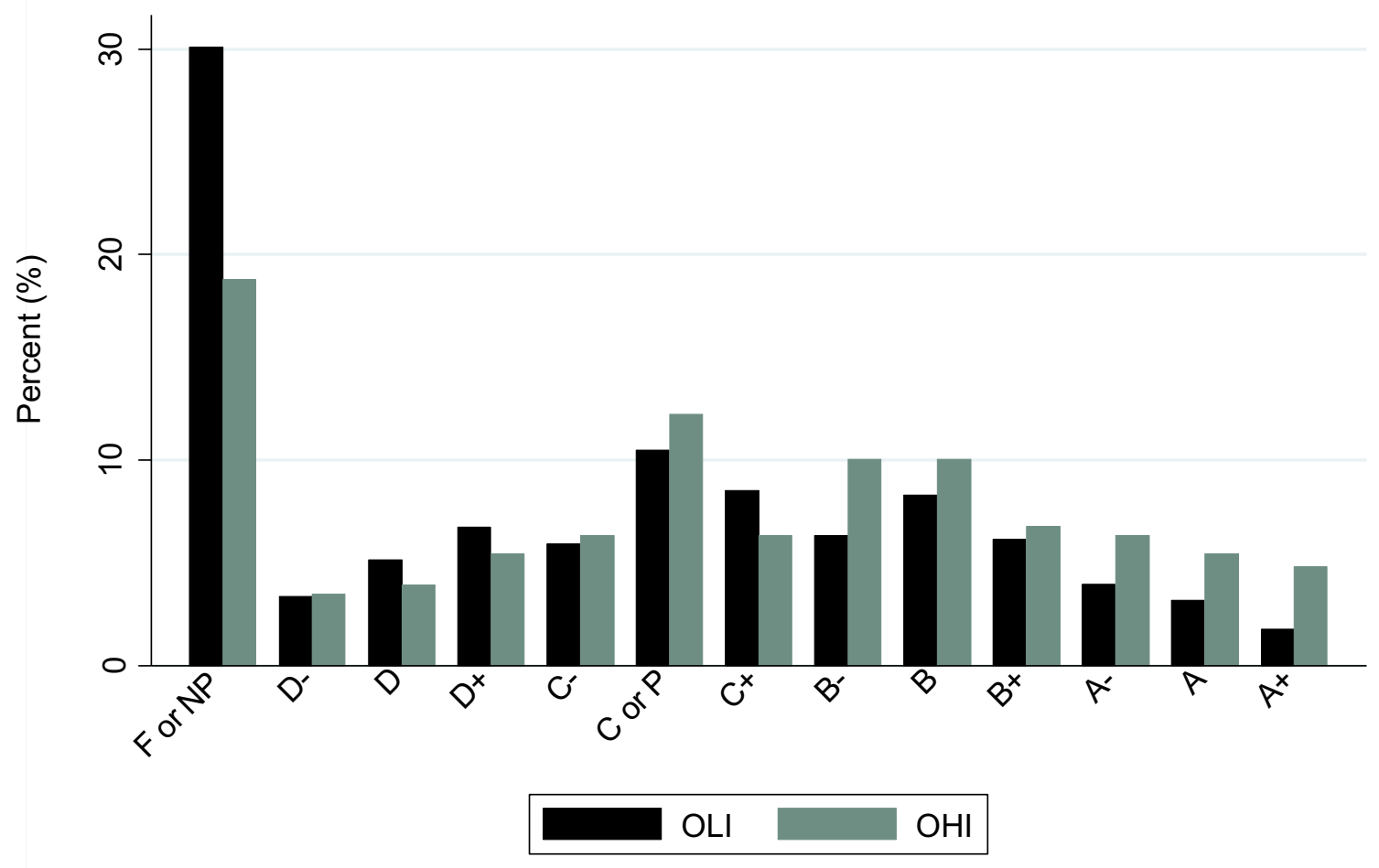

Figure 2. Grade distribution for OLI and OHI conditions. 
Table 5

OHI Treatment Effect on Total Final Exam Subscore

\begin{tabular}{|c|c|c|c|c|}
\hline & $\begin{array}{c}\text { M1 } \\
\text { Full Sample }\end{array}$ & $\begin{array}{c}\text { M2 } \\
\text { Fall Only }\end{array}$ & $\begin{array}{c}\text { M3 } \\
\text { Winter Only }\end{array}$ & $\begin{array}{c}\text { M4 } \\
\text { Full Sample }\end{array}$ \\
\hline $\mathrm{OHI}$ & $\begin{array}{l}4.11 * * \\
(1.45)\end{array}$ & $\begin{array}{l}4.17^{*} \\
(1.78)\end{array}$ & $\begin{array}{l}4.17+ \\
(2.49)\end{array}$ & $\begin{array}{l}4.11 * \\
(1.77)\end{array}$ \\
\hline Winter & $\begin{array}{l}2.54+ \\
(1.50)\end{array}$ & & & $\begin{array}{c}2.55 \\
(2.09)\end{array}$ \\
\hline OHI $\times$ Winter & & & & -0.03 \\
\hline$R$-squared & 0.17 & 0.17 & 0.20 & 0.17 \\
\hline$N$ & 553 & 388 & 165 & 553 \\
\hline
\end{tabular}

Note. Standard errors in parentheses. Models include weights from propensity score matching. M1 and M4 include both fall and winter samples.

$+p<.10{ }^{*} p<.05 . * * p<.01 . * * * p<.001$.

Overall, all models consistently show that the high number of interpersonal interactions increased students' final exam scores, as measured by total points correctly answered divided by total points possible. Focusing on the estimates based on the pooled sample presented in Column 1 , taking the course through the $\mathrm{OHI}$ condition was significantly associated with a higher score by more than four percentage points, which is equivalent to an effect size of 0.22 standard deviations. The effect of OHI was also significant, with similar effect size when estimated based on the fall (Column 2) and winter samples (Column 3) separately.

Table 6 further presents the estimated effects of OHI on final course grades using the same model specifications presented in Table 5. Results based on the pooled sample shown in M1 indicate that students in the $\mathrm{OHI}$ condition received a final grade that was 0.44 grade points higher than their counterparts in the OLI condition, which is approximately equal to an increase from Cto $\mathrm{C}$. Students needed to receive a $\mathrm{C}$ or above in order to pass the precalculus course. In the OLI condition, approximately $6 \%$ of the students received a C-. The benefit of the improved interpersonal condition, given its effect size, may, hence, particularly benefit students on the margin of passing the course. We also examine the extent to which OHI improves the course completion rate, where students need to receive a $\mathrm{C}$ or above in order to pass the precalculus course. Raw comparisons between the two conditions indicate that the OHI group had a much higher course passing rate (62\% vs. 49\%). Subsequent model-adjusted estimation using course passing rate as the outcome based on the full sample (M5 in Table 6) yielded an effect of 0.19, indicating that the OHI condition improved the average probability of passing the precalculus course by 19 percentage points 
Table 6

OHI Treatment Effect on Grade Points and Passing

\begin{tabular}{|c|c|c|c|c|c|}
\hline & M1 & M2 & M3 & M4 & M5 \\
\hline Full Grades & & Fall Grades & $\begin{array}{l}\text { Winter } \\
\text { Grades }\end{array}$ & Full Grades & $\begin{array}{l}\text { Full Pass } \\
\text { Rate }\end{array}$ \\
\hline $\mathrm{OHI}$ & $\begin{array}{c}0.44 * * * \\
(0.11)\end{array}$ & $\begin{array}{c}0.49^{* * * *} \\
(0.13)\end{array}$ & $\begin{array}{c}0.31 \\
(0.22)\end{array}$ & $\begin{array}{c}0.49^{* * *} \\
(0.13)\end{array}$ & $\begin{array}{c}0.19^{* * *} \\
(0.05)\end{array}$ \\
\hline Winter & $\begin{array}{l}0.22+ \\
\quad(0.13)\end{array}$ & & & $\begin{array}{l}0.31+ \\
(0.19)\end{array}$ & $\begin{array}{l}0.21 * * \\
(0.07)\end{array}$ \\
\hline $\mathrm{OHI} \times$ Winter & & & & $\begin{array}{l}-0.18 \\
(0.25)\end{array}$ & $\begin{array}{l}-0.14 \\
(0.10)\end{array}$ \\
\hline$R$-squared & 0.24 & 0.24 & 0.24 & 0.24 & 0.21 \\
\hline$N$ & 553 & 388 & 165 & 553 & 553 \\
\hline
\end{tabular}

Note. Standard errors in parentheses. Grade points are calculated on a 4.0 scale. Models include weights from propensity score matching. M1, M4, and M5 include both fall and winter samples. Grade points is the outcome measure in M1 to M4. Pass (C grades or higher coded as 1) or no pass (below C coded as 0 ) is the outcome measure in M5.

$+p<.10 . * p<.05 . * * p<.01 . * * * p<.001$.

Although the results shown so far indicate that students are fairly balanced based on the matched sample, it is still possible that there might be unobserved differences between the OLI and $\mathrm{OHI}$ groups that are also correlated with student course performance. It is worth noting that the descriptive differences between the OLI and OHI students on observable characteristics indicate that the OHI groups are likely to be lower performing students due to the college-wide policy of lowering admission criteria during the period of this study; this indicates that our current estimate is likely to actually underestimate the positive effect of the OHI condition on student learning outcomes.

That said, we also formally addressed the omitted variable problem by using Rosenbaum's sensitivity analysis (2005) to estimate how large the hidden bias would need to be to overthrow our results. The results indicated that the confidence interval would include 0 in the presence of an upward hidden bias of 5 for both outcome measures; that is, to question our conclusion regarding the positive association between $\mathrm{OHI}$ and student course performance, an unobserved covariate would have to be positively associated with student course performance while increasing the odds of receiving OHI by a factor of five. This effect size is dramatically larger than the association between any of the observed student characteristics and the odds of receiving OHI presented in Table 4, indicating that the current conclusion is extremely robust against potential unobserved covariates.

\section{Discussion}

Online expansion has already become an unstoppable trend in higher education, with an estimated 5-7 million students now enrolling in at least one online course each year. Yet, existing studies have typically found that students do not perform as well in an online course as in a traditional in-person learning environment, particularly among less privileged student populations. 
Increasing Interpersonal Interactions in an Online Course: Does Increased Instructor Email Activity and Voluntary Meeting Time in a Physical Classroom Facilitate Student Learning?

Despite the consensus and urgent need to improve online course effectiveness and student learning outcomes, colleges are faced with a wide and often vague array of recommended online instructional practices with rather limited evidence regarding the benefits of each specific strategy.

In the current study, we describe a specific policy change in a large entry-level college online precalculus course using an adaptive learning system where two practices were implemented in later years to increase interpersonal interactivity: (1) whole-class instructor emails that were sent on a regular basis to keep students on track and (2) a voluntary weekly meeting time in a physical classroom for students to raise content-related questions. Based on a sample of similar students, we found that these practices that intend to increase the interactivity of the course brought about substantial benefits to students. Specifically, students in the higher interactivity condition scored four percentage points higher on their course final exam than students who did not receive the same kind of treatment. The higher level of interpersonal interaction also helped boost student final grades up by almost half a grade.

The effect size of half a letter grade is substantial, considering that almost $13 \%$ of students enrolled in the traditional OLI condition received either a C- or D+ and were therefore on the margin of passing the course (where the threshold is $\mathrm{C}$ or above). Indeed, our analyses on course passing rate indicated that the increased interpersonal interactivity offered in the OHI condition significantly improved course passing rate by 19 percentage points. Since the requirement of retaking precalculus would delay students' enrollment in calculus, the positive impact of OHI on course passing rate is somewhat more consistent with the notion of a threshold or "tipping point" in how a greater level of interpersonal interactivity in a fully online learning environment affects academic progress.

\section{Limitations}

Despite these promising findings, this study also faced several limitations, including the lack of random assignment and the one-year time span of each condition reflected in the data. Although our results indicate that students were fairly balanced based on the matched sample, and the current conclusion is extremely robust against potential unobserved covariates, we cannot rule out the possibility that other time-variant factors might have at least partially contributed to the positive student outcomes observed in later terms. Moreover, the data used in this analysis reflects only a one-year time span for each condition. While the results hold from fall to winter, we were unable to test whether the results were consistent from year to year, whether the findings extended in the same way to later years, and whether subsequent courses were impacted in a similar way. Since the two formats did not have the same instructor across both years in this study, we also cannot confirm whether or not instructor-level factors, such as personality, reputation, and teaching experience, impacted student outcomes. However, instructor influence is reasonably limited since most of the learning took place through the automated online learning system. Nevertheless, it is desirable for future studies to use a completely randomized design to provide experimental evidence regarding the impacts of these practices, both in current and subsequent course outcomes.

Finally, according to the instructor, less than half of the students in the OHI condition attended the weekly meetings in the physical classroom. Furthermore, no record was kept regarding attendance at the meetings, limiting our ability to identify students who ever attended these sessions and the average frequency of attendance. As such, the estimated effect presented in this study represents an average intent-to-treat effect, which may underestimate the actual impact of participating in these weekly meetings on learning outcomes. The data available to us does not 
record which individual students attended the weekly discussion sections, nor does the data contain the characteristics of attending students. Future studies with more detailed student participation records may wish to examine which type of students benefit the most from these voluntary inperson discussion sections. Finally, the majority of the students in our sample lived either on campus or close to campus. As such, students were all within physical distance to attend the inperson meetings. Therefore, the results from the current study may not speak to other online courses where in-person meetings are a significant challenge to students.

Although more research is needed to shed more light on the best practices for teaching an online course, the findings from our study provide important empirical evidence that the effectiveness of semester-long college courses with a high volume of enrollment can be substantially improved through well-structured activities to increase interpersonal interactions. Therefore, colleges that are either currently offering online courses or contemplating replacing inperson courses with online learning may consider implementing similar practices in their online courses. Campuses that cannot provide in-person support in the form of a weekly large lecture meeting (due to space or cost constraints) may want to experiment with other types of support that closely approximate it, such as synchronous online meetings, small group in-person meetings, or targeted-group interventions.

\section{Acknowledgements}

This paper is based upon work supported by the National Science Foundation under Grant Number 1535300. 
Increasing Interpersonal Interactions in an Online Course: Does Increased Instructor Email Activity and Voluntary Meeting Time in a Physical Classroom Facilitate Student Learning?

\section{References}

Acitelli, L., Black, B., \& Axelson, E. (2003). Learning and teaching during office hours. Center for Research on Learning and Teaching, University of Michigan. Retrieved January 3, 2009, from http://www.crlt.umich.edu/gsis/p4 5

Allen, I. E., \& Seaman, J. (2014). Grade change: Tracking online education in the United States, 2013. Babson Survey Research Group and Quahog Research Group, LLC. Retrieved from www.onlinelearningsurvey.com/reports/gradechange.pdf

An, H., Shin, S., \& Lim, K. (2009). The effects of different instructor facilitation approaches on students' interactions during asynchronous online discussions. Computers \& Education, 53(3), 749-760.

Anderson, T. (2003). Getting the mix right again: An updated and theoretical rationale for interaction. The International Review of Research in Open and Distributed Learning, $4(2)$.

Asarta, C. J., \& Schmidt, J. R. (2013). Access patterns of online materials in a blended course. Decision Sciences Journal of Innovative Education, 11(1), 107-123.

Attewell, P., Lavin, D., Domina, T., \& Levey, T. (2006). New evidence on college remediation. Journal of Higher Education, 77(5), 886-924

Austin, P. C. (2011). An introduction to propensity score methods for reducing the effects of confounding in observational studies. Multivariate Behavioral Research, 46(3), 399-424.

Bahr, P. R. (2010). Making sense of disparities in mathematics remediation: What is the role of student retention? Journal of College Student Retention: Research, Theory \& Practice, $12(1), 25-49$.

Berge, Z. L. (1999). Interaction in post-secondary web-based learning. Educational Technology, $39(1), 5-11$.

Bernard, R. M., Abrami, P. C., Borokhovski, E., Wade, C. A., Tamim, R. M., Surkes, M. A., \& Bethel, E. C. (2009). A meta-analysis of three types of interaction treatments in distance education. Review of Educational Research, 79(3), 1243-1289.

Bippus, A. M., Kearney, P., Plax, T. G., \& Brooks, C. F. (2003). Teacher access and mentoring abilities: Predicting the outcome value of extra class communication. Journal of Applied Communication Research, 31(3), 260-275.

Bonham, B. S., \& Boylan, H. R. (2011). Developmental mathematics: Challenges, promising practices, and recent initiatives. Journal of Developmental Education, 34(3), 2.

Chen, X., \& Simone, S. (2016). Remedial coursetaking at US public 2-and 4-year institutions: Scope, experiences, and outcomes. Washington, DC: National Center for Education Statistics, Institute of Education Sciences, U.S. Department of Education. Retrieved from http://files.eric.ed.gov/fulltext/ED568682.pdf

Cho, M. H., \& Cho, Y. (2016). Online instructors' use of scaffolding strategies to promote interactions: A scale development study. The International Review of Research in Open and Distributed Learning, 17(6). 
Increasing Interpersonal Interactions in an Online Course: Does Increased Instructor Email Activity and Voluntary Meeting Time in a Physical Classroom Facilitate Student Learning?

Cho, M. H., \& Heron, M. L. (2015). Self-regulated learning: The role of motivation, emotion, and use of learning strategies in students' learning experiences in a self-paced online mathematics course. Distance Education, 36(1), 80-99.

Cho, M. H., \& Kim, B. J. (2013). Students' self-regulation for interaction with others in online learning environments. The Internet and Higher Education, 17, 69-75.

Chou, C. (2003). Interactivity and interactive functions in web-based learning systems: A technical framework for designers. British Journal of Educational Technology, 34(3), $265-279$.

Coates, D., Humphreys, B. R., Kane, J., \& Vachris, M. A. (2004). "No significant distance" between face-to-face and online instruction: Evidence from principles of economics. Economics of Education Review, 23, 533-546.

Fain, P. (2013, July 19). Free courses for a big problem. Inside Higher Education. Retrieved from https://www.insidehighered.com/news/2013/07/19/two-year-colleges-go-opensource-seek-fix-remediation

Figlio, D. N., Rush, M., \& Yin, L. (2013). Is it live or is it internet? Experiment estimates of the effects of online instruction on student learning. Journal of Labor Economics, 31, 763784.

Fredericksen, E., Pickett, A., Shea, P., Pelz, W., \& Swan, K. (2000). Student satisfaction and perceived learning with on-line courses: Principles and examples from the SUNY learning network. Journal of Asynchronous Learning Networks, 4(2), 7-41.

Friesen, N., \& Kuskis, A. (2013). Modes of interaction. In M. G. Moore (Ed.), Handbook of distance education (3rd ed., pp. 351-371). New York, NY: Routledge.

Fulford, C. P., \& Zhang, S. (1993). Perceptions of interaction: The critical predictor in distance education. The American Journal of Distance Education, 7(3), 8-21.

Griffin, W., Cohen, S. D., Berndtson, R., Burson, K. M., Camper, K. M., Chen, Y., \& Smith, M. A. (2014). Starting the conversation: An exploratory study of factors that influence student office hour use. College Teaching, 62(3), 94-99.

Gunawardena, C. N., \& Zittle, F. J. (1997). Social presence as a predictor of satisfaction within a computer-mediated conferencing environment. The American Journal of Distance Education, 11(3), 8-26.

Hara, N. (2000). Student distress in a web-based distance education course. Information, Communication \& Society, 3(4), 557-579.

Hassini, E. (2006). Student-instructor communication: The role of email. Computers \& Education, 47(1), 29-40.

Hew, K. F., Cheung, W. S., \& Ng, C. S. L. (2010). Student contribution in asynchronous online discussion: A review of the research and empirical exploration. Instructional science, $38(6), 571-606$.

Jaasma, M. A., \& Koper, R. J. (1999). The relationship of student-faculty out-of-class communication to instructor immediacy and trust and to student motivation. Communication Education, 48(1), 41-47. 
Increasing Interpersonal Interactions in an Online Course: Does Increased Instructor Email Activity and Voluntary Meeting Time in a Physical Classroom Facilitate Student Learning?

Jaggars, S. S., \& Xu, D. (2016). How do online course design features influence student performance? Computers \& Education, 95, 270-284.

Jiang, M., \& Ting, E. (1999). A study of students' perceived learning in a web-based online environment. Proceedings of WebNet World Conference on the WWW and the Internet. Retrieved from https://www.learntechlib.org/j/WEBNETC/v/1999/n/1/

Kang, M., \& Im, T. (2013). Factors of learner-instructor interaction which predict perceived learning outcomes in online learning environment. Journal of Computer Assisted Learning, 29(3), 292-301.

Kearsley, G. (1995). The nature and values of interaction in distance education. In Third Distance Education Research Symposium. University Park, PA: American Center for the Study of Distance Education.

Mandernach, B. J., Forrest, K. D., Babutzke, J. L., \& Manker, L. R. (2009). The role of instructor interactivity in promoting critical thinking in online and face-to-face classrooms. MERLOT Journal of Online Learning and Teaching, 5(1), 49-62.

McGee, D., Vasquez, P. \& Cajigas, J. (2014). A comparison between a traditional and an accelerated, online, adaptive approach to developmental mathematics. Journal of Computers in Mathematics and Science Teaching, 33(4), 429-453.

Moore, M.G. (1989). Three types of interaction. American Journal of Distance Education, 3(2), $1-7$.

Moore, M. G. (2013). The theory of transactional distance. In M. G. Moore (Ed.), Handbook of distance education (pp. 84-103). New York, NY: Routledge.

Moore, M. G., \& Kearsley, G. (1996). Distance education: A systems view. Belmont, CA: Wadsworth.

Nadler, M. K., \& Nadler, L. B. (2000). Out of class communication between faculty and students: A faculty perspective. Communication Studies, 51(2), 176-188.

Northrup, P. T. (2002). Online learners' preferences for interaction. Quarterly Review of Distance Education, 3(2), 219-26.

Parsad, B., Lewis, L., \& Greene, B. (2003). Remedial education at higher education institutions in fall 2000. Retrieved from http://nces.ed.gov/pubs2004/2004010.pdf

Picciano, A. G. (2001). Distance learning: Making connections across virtual space and time. Upper Saddle River, NJ: Prentice-Hall.

Radford, A. W., \& Horn, L. (2012). An overview of classes taken and credits earned by beginning postsecondary students. Washington, DC: National Center for Education Statistics, Institute of Education Sciences, U.S. Department of Education. Retrieved from https://nces.ed.gov/pubs2013/2013151rev.pdf

Rosenbaum, P. R. (2005). Sensitivity analysis in observational studies. In B. S. Everitt \& D. C. Howell (Eds.), Encyclopedia of statistics in behavioral science (pp. 1809 -1814). New York: Wiley.

Salmon, G. (2002). E-tivities: The key to active online learning. London, United Kingdom: Kogan Page. 
Increasing Interpersonal Interactions in an Online Course: Does Increased Instructor Email Activity and Voluntary Meeting Time in a Physical Classroom Facilitate Student Learning?

Salmon, G. (2004). E-moderating: The key to teaching and learning on-line. London, United Kingdom: Kogan Page.

Scardamalia, M., \& Bereiter, C. (2006). Knowledge building: Theory, pedagogy, and technology. In K. Sawyer (Ed.), Cambridge handbook of the learning sciences (pp. 97118). New York, NY: Cambridge University Press.

Schunk, D. H., Pintrich, P. R. \& Meece, J. L. (2008). Motivation in education: Theory, research, and applications (3rd ed.). Upper Saddle River, NJ: Pearson Education Inc.

Shearer, R. (2013). Theory to practice in instructional design. In M. G. Moore (Ed.), Handbook of distance education (3rd ed., pp. 251-267). New York, NY: Routledge.

Sherry, L. (1995). Issues in distance learning. International Journal of Educational Telecommunications, 1(4), 337-365.

Short, J., Williams, E., \& Christie, B. (1976). The social psychology of telecommunications.

London, UK: Wiley.

Skomsvold, P. (2014). Profile of undergraduate students: 2011-12. Washington, DC: National Center for Education Statistics, Institute of Education Sciences, U.S. Department of Education. Retrieved from https://nces.ed.gov/pubs2015/2015167.pdf

Sparks, D., \& Malkus, N. (2013). First-year undergraduate remedial coursetaking: 1999-2000, 2003-04, 2007-08. Statistics in Brief. NCES 2013-013. National Center for Education Statistics.

Su, B., Bonk, C. J., Magjuka, R. J., Liu, X., \& Lee, S. H. (2005). The importance of interaction in web-based education: A program-level case study of online MBA courses. Journal of Interactive Online Learning, 4(1), 1-19.

Swan, K., Shea, P., Fredericksen, E., Pickett, A., Pelz, W., \& Maher, G. (2000). Building knowledge building communities: Consistency, contact and communication in the virtual classroom. Journal of Educational Computing Research, 23(4), 359-383.

Weimer, M. (2015, January 21). Why students don't attend office hours [Blog entry]. Retrieved from https://www.facultyfocus.com/articles/teaching-professor-blog/students-dontattend-office-hours/

Xu, D., \& Jaggars, S. S. (2011). The effectiveness of distance education across Virginia's community colleges: Evidence from introductory college-level math and English courses. Educational Evaluation and Policy Analysis, 33(3), 360-377.

Xu, D., \& Jaggars, S. S. (2013). Adaptability to online learning: Differences across types of students and academic subject areas. CCRC Working Paper No. 54. Community College Research Center, Columbia University.

Xu, D., \& Jaggars, S. S. (2014). Performance gaps between online and face-to-face courses: Differences across types of students and academic subject areas. Journal of Higher Education, 85(5), 633-659.

Young, S. (2006). Student views of effective online teaching in higher education. American Journal of Distance Education, 20(2), 65-77. 
Increasing Interpersonal Interactions in an Online Course: Does Increased Instructor Email Activity and Voluntary Meeting Time in a Physical Classroom Facilitate Student Learning?

\section{Appendix A}

Table A1

PSM Balance Check for Fall Students

\begin{tabular}{|c|c|c|c|c|c|c|c|}
\hline \multirow[b]{2}{*}{ Variable } & & \multicolumn{3}{|c|}{ Mean } & \multicolumn{3}{|c|}{ Standard Deviation } \\
\hline & & $2013-14$ & $2012-13$ & Diff. & $2013-14$ & $2012-13$ & Ratio \\
\hline \multirow[t]{2}{*}{ Initial Assessment } & Unmatched & 24.48 & 23.62 & -0.06 & 15.93 & 14.95 & 0.94 \\
\hline & Matched & 21.00 & 21.53 & 0.04 & 8.97 & 9.83 & 1.09 \\
\hline \multirow[t]{2}{*}{ SAT Math Score } & Unmatched & -0.74 & -0.70 & 0.07 & 0.70 & 0.57 & 0.81 \\
\hline & Matched & -0.78 & -0.74 & 0.07 & 0.49 & 0.51 & 1.04 \\
\hline \multirow[t]{2}{*}{ SAT Verbal Score } & Unmatched & -1.01 & -0.92 & 0.13 & 0.87 & 0.74 & 0.84 \\
\hline & Matched & -1.02 & -0.97 & 0.08 & 0.64 & 0.62 & 0.97 \\
\hline \multirow[t]{2}{*}{ Female } & Unmatched & 0.57 & 0.58 & 0.02 & 0.50 & 0.49 & 1.00 \\
\hline & Matched & 0.59 & 0.59 & 0.00 & 0.49 & 0.49 & 1.00 \\
\hline \multicolumn{8}{|l|}{ Ethnicity } \\
\hline \multirow[t]{2}{*}{ Asian } & Unmatched & 0.32 & 0.23 & -0.20 & 0.47 & 0.42 & 0.91 \\
\hline & Matched & 0.26 & 0.26 & 0.00 & 0.44 & 0.44 & 1.00 \\
\hline \multirow[t]{2}{*}{ Black } & Unmatched & 0.05 & 0.05 & -0.02 & 0.22 & 0.21 & 0.96 \\
\hline & Matched & 0.02 & 0.02 & 0.00 & 0.14 & 0.14 & 1.00 \\
\hline \multirow[t]{2}{*}{ Hispanic } & Unmatched & 0.44 & 0.48 & 0.10 & 0.50 & 0.50 & 1.01 \\
\hline & Matched & 0.59 & 0.59 & 0.00 & 0.49 & 0.49 & 1.00 \\
\hline \multirow[t]{2}{*}{ White } & Unmatched & 0.13 & 0.12 & -0.03 & 0.33 & 0.32 & 0.97 \\
\hline & Matched & 0.08 & 0.08 & 0.00 & 0.27 & 0.27 & 1.00 \\
\hline \multirow[t]{2}{*}{ Other } & Unmatched & 0.07 & 0.12 & 0.15 & 0.26 & 0.33 & 1.26 \\
\hline & Matched & 0.05 & 0.05 & 0.00 & 0.21 & 0.21 & 1.00 \\
\hline \multirow[t]{2}{*}{ Major Requires Math } & Unmatched & 0.60 & 0.40 & -0.40 & 0.49 & 0.49 & 1.00 \\
\hline & Matched & 0.43 & 0.43 & 0.00 & 0.50 & 0.50 & 1.00 \\
\hline \multirow[t]{2}{*}{ Freshman } & Unmatched & 0.76 & 0.83 & 0.20 & 0.43 & 0.37 & 0.87 \\
\hline & Matched & 0.88 & 0.88 & 0.00 & 0.33 & 0.33 & 1.00 \\
\hline
\end{tabular}

Note. "Matched" shows the matched estimates using Mahalanobis distances and kernel matching with a bandwidth of 1.5. Students in the treatment group received face-to-face support while students in the control group did not. SAT Math and Verbal scores are centered at a score of 600 (the cutoff score for students who would like to skip to the next math course) and have been divided by 100 . 
Table A2

PSM Balance Check for Winter Students

\begin{tabular}{|c|c|c|c|c|c|c|c|}
\hline \multirow[b]{2}{*}{ Variable } & & \multicolumn{3}{|c|}{ Mean } & \multicolumn{3}{|c|}{$\underline{\text { Standard Deviation }}$} \\
\hline & & $2013-14$ & $2012-13$ & Diff. & 2013-14 & $2012-13$ & Ratio \\
\hline \multirow[t]{2}{*}{ Initial Assessment } & Unmatched & 23.65 & 23.08 & -0.04 & 15.72 & 14.59 & 0.93 \\
\hline & Matched & 21.58 & 21.54 & 0.00 & 9.45 & 9.52 & 1.01 \\
\hline \multirow[t]{2}{*}{ SAT Math Score } & Unmatched & -0.92 & -0.67 & 0.52 & 0.73 & 0.48 & 0.66 \\
\hline & Matched & -0.70 & -0.67 & 0.06 & 0.47 & 0.39 & 0.82 \\
\hline \multirow[t]{2}{*}{ SAT Verbal Score } & Unmatched & -1.13 & -0.73 & 0.59 & 0.81 & 0.66 & 0.82 \\
\hline & Matched & -0.89 & -0.84 & 0.08 & 0.54 & 0.50 & 0.93 \\
\hline \multirow[t]{2}{*}{ Female } & Unmatched & 0.68 & 0.72 & 0.09 & 0.47 & 0.45 & 0.97 \\
\hline & Matched & 0.80 & 0.80 & 0.00 & 0.40 & 0.40 & 1.00 \\
\hline \multicolumn{8}{|l|}{ Ethnicity } \\
\hline \multirow[t]{2}{*}{ Asian } & Unmatched & 0.29 & 0.32 & 0.05 & 0.46 & 0.47 & 1.02 \\
\hline & Matched & 0.29 & 0.29 & 0.00 & 0.46 & 0.46 & 1.00 \\
\hline \multirow[t]{2}{*}{ Black } & Unmatched & 0.05 & 0.06 & 0.07 & 0.21 & 0.24 & 1.15 \\
\hline & Matched & 0.03 & 0.03 & 0.00 & 0.16 & 0.16 & 1.00 \\
\hline \multirow[t]{2}{*}{ Hispanic } & Unmatched & 0.48 & 0.47 & -0.01 & 0.50 & 0.50 & 1.00 \\
\hline & Matched & 0.58 & 0.58 & 0.00 & 0.50 & 0.50 & 1.00 \\
\hline \multirow[t]{2}{*}{ White } & Unmatched & 0.09 & 0.10 & 0.01 & 0.29 & 0.29 & 1.02 \\
\hline & Matched & 0.08 & 0.08 & 0.00 & 0.27 & 0.27 & 1.00 \\
\hline \multirow[t]{2}{*}{ Other } & Unmatched & 0.09 & 0.05 & -0.16 & 0.29 & 0.23 & 0.79 \\
\hline & Matched & 0.03 & 0.03 & 0.00 & 0.16 & 0.16 & 1.00 \\
\hline \multirow[t]{2}{*}{ Major Requires Math } & Unmatched & 0.54 & 0.47 & -0.15 & 0.50 & 0.50 & 1.00 \\
\hline & Matched & 0.47 & 0.47 & 0.00 & 0.50 & 0.50 & 1.00 \\
\hline \multirow[t]{2}{*}{ Freshman } & Unmatched & 0.81 & 0.77 & -0.10 & 0.39 & 0.42 & 1.08 \\
\hline & Matched & 0.87 & 0.87 & 0.00 & 0.34 & 0.34 & 1.00 \\
\hline
\end{tabular}

Note. "Matched" shows the matched estimates using Mahalanobis distances and kernel matching with a bandwidth of 1.5. Students in the treatment group received face-to-face support while students in the control group did not. SAT Math and Verbal scores are centered at a score of 600 (the cutoff score for students who would like to skip to the next math course) and have been divided by 100 . 